\title{
Soil-transmitted Helminths and Urinary Schistosomiasis Co-infection: Risk Factors among School Children in Riverine Areas of Wamakko Local Government, Sokoto State, Nigeria
}

\author{
Muhammad Imrana Arzika*, Bala Aminu Yabo \\ Department of Biological Sciences, Usmanu Danfodiyo University, Nigeria
}

Received March 5, 2020; Revised May 27, 2020; Accepted June 4, 2020

\section{Cite This Paper in the following Citation Styles}

(a): [1] Muhammad Imrana Arzika, Bala Aminu Yabo, "Soil-transmitted Helminths and Urinary Schistosomiasis Co-infection: Risk Factors among School Children in Riverine Areas of Wamakko Local Government, Sokoto State, Nigeria," Advances in Zoology and Botany, Vol. 8, No. 5, pp. 375 - 382, 2020. DOI: 10.13189/azb.2020.080501.

(b): Muhammad Imrana Arzika, Bala Aminu Yabo (2020). Soil-transmitted Helminths and Urinary Schistosomiasis Co-infection: Risk Factors among School Children in Riverine Areas of Wamakko Local Government, Sokoto State, Nigeria. Advances in Zoology and Botany, 8(5), 375 - 382. DOI: 10.13189/azb.2020.080501.

Copyright $\bigcirc 2020$ by authors, all rights reserved. Authors agree that this article remains permanently open access under the terms of the Creative Commons Attribution License 4.0 International License

\begin{abstract}
Epidemiological study was conducted to determine the prevalence of urinary schistosomiasis and intestinal helminth co-infection among primary school pupils in Wamakko Local Government, Sokoto State, Nigeria. Urine and stool samples were collected from 400 pupils and analyzed using filtration and formol-ether concentration techniques respectively. Out of 400 samples, $63(32.8 \%)$ were co-infected with Schistosoma haematobium and one or more intestinal helminths. The co-infection of $S$. haematobium with Ascaris lumbricoides was most prevalent (74.6\%), while $S$. haematobium with $A$. lumbricoides, hookworm, and $S$. haematobium with $A$. lumbricoides and $S$. mansoni had the least prevalence (1.6\% each). Being male, 10-12 years of age and not washing hands before and after meals were the major risk factors for the spread of urinary schistosomiasis and intestinal helminths co-infection in the study area. An integrated strategy that involves the provision of health education to the communities, regular treatments, provision of safe water supply and sanitation facilities is highly recommended.
\end{abstract}

Keywords Urinary Schistosomiasis, Wamakko, School Children, Soil-transmitted Helminths, Co-infection

\section{Introduction}

Schistosomiasis and intestinal helminthiasis pose major health and socio-economic problems in developing countries $[1,2]$.

More than two billion people are estimated to be infected with schistosomiasis and intestinal helminthiasis worldwide, of which over 300 million suffer from associated severe morbidity [3]. Schistosomiasis is a major cause of morbidity and mortality for developing countries in Africa, South America, Caribbean, Middle East, and Asia [4].

Over 610 million school-aged children are at risk due to schistosomiasis and soil-transmitted helminthiasis [5]. School-aged children, compared to any other age group, are the most susceptible group and harbor the greatest numbers of worms. Consequently, they experience stunted growth, reduced physical fitness, impaired academic performance and reduced attendance to school [6-8]. Helminthic co-infection is closely tied to socio-economic, environmental and other factors such as ignorance, overcrowding, lack of clean water and tropical climate $[9$, $10]$.

Humans become infected with these infections when they ingest infective eggs (Ascaris lumbricoides and Trichuris trichiura) or larvae (Ancylostoma duodenale) or through skin penetration of infective larvae contaminating 
the soil (Necator americanus and Strongyloides stercoralis) or freshwater (schistosomes) [5].

Schistosomiasis and intestinal helminthiasis cause morbidity or even death by adversely affecting the nutritional status of the host, impairing cognitive processes, causing complications that require surgical intervention and inducing reaction in tissues [5].

Most parasitological field researches in tropical areas are focused on a single parasite, despite, in reality, the subjects are usually infected with two or more species of parasites concurrently. The pattern of distribution of parasite species among hosts is in part determined, among other things, by host genetics, physiology, nutrition, and socioeconomic status. Hosts concurrently infected with more than one species of the parasite are not only at infection risk with each parasite species but also with more severe diseases due to synergistic interaction among parasite species $[6,7]$.

Co-infection (or polyparasitism) is defined as the concurrent presence of different parasite species in a single host [11]. Co-infection is ubiquitous in people in the developing countries, but little is known regarding the potential for one parasite to act as a risk factor for another [12]. Concurrent schistosomiasis and co-infection with soil-transmitted occur alongside each other with other tropical diseases and with a wide range of co-infecting organisms. Studies have demonstrated that areas with high prevalence of schistosomiasis are also endemic for soil-transmitted helminthiasis [13].

Soil-transmitted helminthiasis and urinary schistosomiasis are endemic in all regions of Africa and their public health importance has been described by many researchers $[14,15,16,17,18,19,20]$. Studies on concurrent schistosomiasis and co-infection with helminths parasites are few. This study was designed to provide current epidemiological data with regards to the prevalence and of urinary schistosomiasis and intestinal helminth co-infection in Wamakko local government of Sokoto State in Nigeria.

\section{Materials and Methods}

\subsection{Study Area}

The study was conducted in the Wamakko Local Government of Sokoto State, Nigeria. Wamakko local government comprises of the following districts: Wamakko, Gumbi, Dundaye, and Gumburawa (Figure 1). The major occupations of the inhabitants are farming and fishing and minor occupations such as laundry and trading. The local government was populated by the Hausa people. Wamakko local government is located in the north-west geopolitical zone of Nigeria and lies between latitude $12^{\circ} \mathrm{N}$ - $13^{0} 58 \mathrm{~N}$ and longitude $04^{\circ} 8^{\prime} \mathrm{E}-6^{\circ} 65 \mathrm{E}$. The local governments share borders with Sokoto North, Sokoto South, Kware, Binji, Silame, Bodinga, Yabo and Tangaza local governments of Sokoto State [21]. These four primary schools were selected: Kaura Kimba, Wajeke, Tangwale, and Gidan Bubu. 


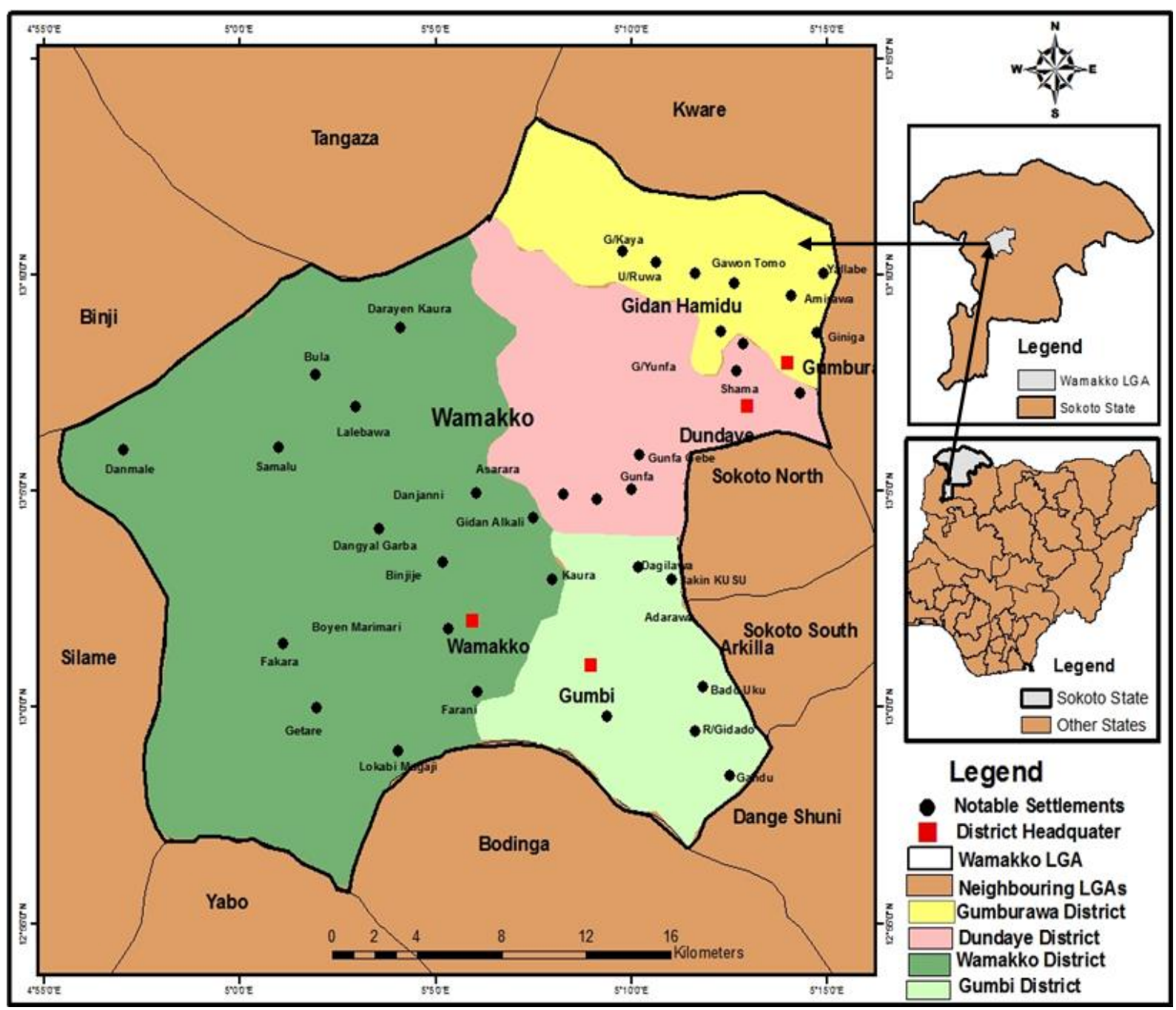

Source: Arc map

Drawn by Abubakar Salah Dept. of Geography UDUS (2017)

Figure 1. Map of Nigeria, Sokoto State and Wamakko Local Government Area Showing the four surveyed districts

\subsection{Sample Population}

The study population was made up of primary school pupils. Participants not enrolled in primary schools were excluded from the study.

\subsection{Ethical Consideration}

Ethical consideration was obtained from Wamakko local government Education Authority. Informed consent was obtained from parents/guardians of the pupils after explaining the purpose and procedure of the study. Subjects were not forced and were free to withdraw at any stage of the study.

\subsection{Sample Collection}

Four hundred samples each of stool and urine were collected between 10:00 am- 2:00 pm from four hundred school pupils. Each pupil was given two sterile, labeled clean screw-capped containers and guided on how to collect stool and urine samples. Collected stool and urine samples were transported to Parasitology Laboratory, Department of Biological Sciences, Usmanu Danfodiyo University, Sokoto, Nigeria for analysis.

Stool samples were analyzed using the Formol-ether concentration technique [22]. Eggs and larvae of intestinal helminths were identified according to the chart provided by WHO [23].

The urine samples were analyzed for the presence of $S$. haematobium using standard filtration technique [24]. Eggs with a terminal spine, the characteristic of $S$. haematobium, were counted for each sample found positive and reported as eggs $/ 10 \mathrm{ml}$ of urine.

\subsection{Determination of Nutritional Status}

Anthropometric measurements were taken [25]. Bathroom scale was used to measure the pupil's weight while height was measured using tape rule. The nutritional status was based on Body Mass Index (BMI) for age [26], where BMI $=$ Weight $(\mathrm{kg}) /$ Height $\left(\mathrm{m}^{2}\right)$. 


\subsection{Questionnaire Administration}

A well-structured questionnaire was administered to each pupil from whom samples were collected to obtain information such as sex, age, the source of drinking water, water contact activity, type of toilet and body hygiene. Questionnaires were interpreted in their local language and assisted in completing them. Each questionnaire was numbered to correspond to the number labeled on the pupil's urine/stool container.

\subsection{Data Analysis}

Chi-square $\left(\chi^{2}\right)$ statistical analysis and then multivariate analysis with binary logistic multiple regression were used to determine the association between parasitism and risk factors (school, sex, age, the source of drinking water, water contact activity, type of toilet, body hygiene, and nutritional status). $\mathrm{P}$ values less than 0.05 were considered significant. Data were analyzed using Quantitative Parasitological Software Ver. 3.0.

\section{Results}

A total of 400 primary school pupils were included in the survey of four primary schools of Wamakko local government. The five most common parasites encountered during the study are as follows: A. lumbricoides $85.1 \%, S$. haematobium $48.0 \%$, S. stercoralis $10.8 \%$, hookworm (Ancylostoma duodenale and Necator americanus) 2.0\%, and S. mansoni, $2.0 \%$. Of these, 63 pupils were found to be co-infected with $S$. haematobium and intestinal helminths with a prevalence of $32.8 \%$ (Table 1).

Two types of parasite combinations were encountered in this study. A combination of $S$. haematobium with one other parasite was encountered in 52 pupils while 11 pupils had $S$. haematobium with two other parasites. The co-infection of $S$. haematobium and A. lumbricoides was identified in $47(74.6 \%)$ of 63 pupils, which was significantly more prevalent than $S$. haematobium $+A$. lumbricoides+ hookworm co-infection $(14.3 \%)(P<0.05)$ (Fig. 1).

Table 1. Prevalence and Intensity of Urinary Schistosomiasis and Intestinal Helminth Co-infection among Primary School Pupils in Wamakko Local Government Area, Sokoto.

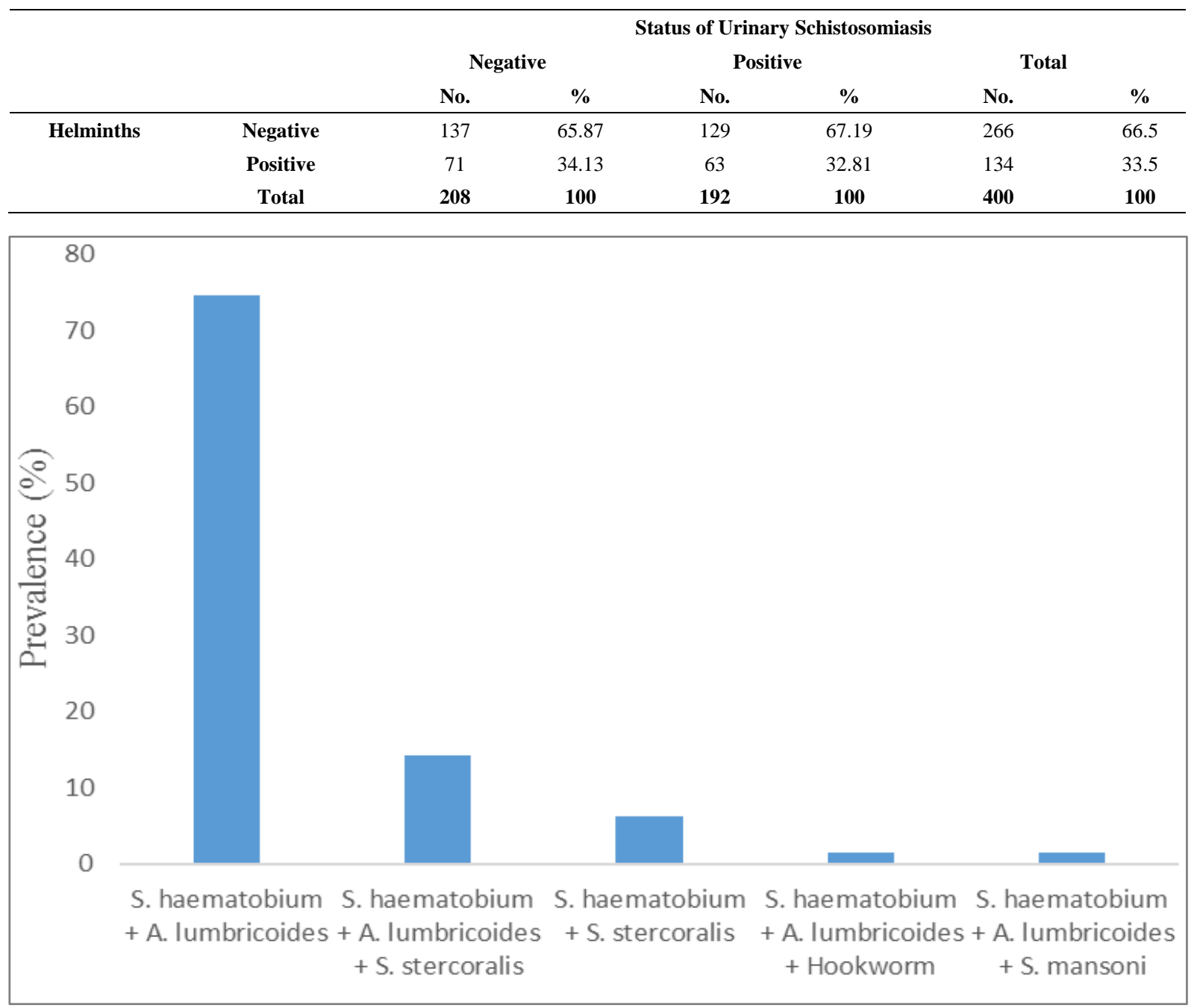

Figure 2. Prevalence of parasites co-infection in Wamakko Local Government Area, Sokoto, Nigeria. 
The co-infection was highest in pupils from Tangwale primary school (12.5\%), followed by Gidan Bubu (8.9\%) and Kaura Kimba (6.8\%), while pupils in Wajeke had the least prevalence $(4.7 \%)$. Chi-square analysis indicated no significant association of parasite co-infection with school $(P>0.05)$ (Table 2).

The co-infection of parasites was identified significantly more in boys (26.4\% in boys, $16.7 \%$ in girls; $\mathrm{p}<0.05)$ (Table 3). Co-infection rates were elevated with age and suddenly dropped at 13 years and above. Age group-specific prevalence of the co-infection showed that pupils aged 10-12 years had the highest prevalence (14.6\%) followed by $7-9$ years $(9.4 \%), 13$ years and above $(4.7 \%)$, and 4-6 years with least prevalence $(4.2 \%)$. There is a significant association between parasite co-infection with age group $(P<0.05)$ (Table 3$)$.

The prevalence of co-infection in relation to the source of drinking water was presented in Table 4. Prevalence of co-infection in relation to water contact activity indicated that pupils who could not mention their water contact activity recorded the highest prevalence, while those who go to the river to feed animals had the least prevalence. The occurrence of parasitic co-infection significantly associates with water contact activity $(P<0.05)$ (Table 4$)$.

The results of this study revealed that pupils who defecate in an open space had a higher prevalence of co-infection $(24.0 \%)$ compared to those who use pit latrine $(8.9 \%)$. However, no significant association was observed in the occurrence of co-infection and type of toilet $(P>0.05)$ in Table 5. The prevalence of the co-infection in relation to nutritional status indicated that underweight pupils recorded the highest prevalence (24.0\%), then those whose nutritional status is within the normal range $(7.8 \%)$, while obese pupils were the least infected (1.0\%). Chi-square statistical analysis revealed no significant association between the occurrence of co-infection and the nutritional status of the pupils $(P>0.05)$ (Table 5).

The occurrence of parasite co-infection significantly associates with the pupil's body hygiene $(P<0.05)$. Pupils who do not wash their hands before and after eating recorded the highest prevalence (32.3\%). Pupils who do not wash their hands after the toilet and who walk barefooted had $27.6 \%$ and $15.1 \%$ infection rates respectively (Table 6).

Table 2. School and Class Prevalence of Urinary Schistosomiasis and Intestinal Helminth Co-Infection among Primary School Pupils in Wamakko Local Government Area, Sokoto

\begin{tabular}{ccc}
\hline Parameters & $\begin{array}{c}\text { No. Infected } \\
\mathbf{n = 1 9 2}\end{array}$ & Prevalence (\%) \\
\hline School & & \\
Wajeke & 9 & 4.7 \\
Tangwale & 24 & 12.5 \\
Kaura Kimba & 13 & 6.8 \\
Gidan Bubu & 17 & 8.9 \\
\hline
\end{tabular}

Table 3. Sex and Age-Specific Prevalence of Urinary Schistosomiasis and Intestinal Helminth Co-Infection among Primary School Pupils in Wamakko Local Government Area, Sokoto

\begin{tabular}{ccc}
\hline Parameters & $\begin{array}{c}\text { No. Infected } \\
\mathbf{n = 1 9 2}\end{array}$ & Prevalence (\%) \\
\hline Sex & 50 & \\
Males & 32 & 26.0 \\
Females & & 16.7 \\
& & \\
Ages (Years) & 8 & 4.2 \\
4-6 years & 18 & 9.4 \\
7-9 years & 28 & 14.6 \\
10-12 years & 9 & 4.7 \\
13+ years \& above & & \\
\hline
\end{tabular}

Table 4. Prevalence of Urinary Schistosomiasis and Intestinal Helminth Co-Infection among Primary School Pupils in Wamakko Local Government Area in Relation to Source of Drinking Water and Water Contact Activity

\begin{tabular}{ccc}
\hline Parameters & $\begin{array}{c}\text { No. Infected } \\
\mathbf{n}=\mathbf{1 9 2}\end{array}$ & $\begin{array}{c}\text { Prevalence } \\
(\mathbf{\%})\end{array}$ \\
\hline Source of Drinking & & \\
water & 1 & 0.5 \\
River & 13 & 6.8 \\
Tap & 49 & 25.5 \\
Well & & \\
& & \\
Water contact activity & & \\
Bathing & 17 & 8.9 \\
Irrigation Farming & 2 & 1.0 \\
Feeding Animals & 1 & 0.5 \\
Fetching & 9 & 4.7 \\
Passing & 0 & 0.0 \\
Washing & 3 & 1.6 \\
Do not know & 31 & 16.2 \\
\hline
\end{tabular}

Table 5. Prevalence of Urinary Schistosomiasis and Intestinal Helminth Co-Infection among Primary School Pupils with Relation to Type of Toilet and Nutritional Status

\begin{tabular}{ccc}
\hline Parameters & $\begin{array}{c}\text { No. Infected } \\
\mathbf{n = 1 9 2}\end{array}$ & $\begin{array}{c}\text { Prevalence } \\
(\boldsymbol{\%})\end{array}$ \\
\hline Type of Toilet & & \\
Open space & 46 & 24.0 \\
Pit latrine & 17 & 8.9 \\
& & \\
Nutritional Status & & \\
Normal & 15 & 7.8 \\
Obese & 2 & 1.0 \\
Underweight & 46 & 24.0 \\
\hline
\end{tabular}

Table 6. Prevalence of Urinary Schistosomiasis and Intestinal Helminths Co-Infection among Primary School Pupils in Wamakko Local Government Area, Sokoto with Respect to Body Hygiene

\begin{tabular}{ccc}
\hline Parameters & $\begin{array}{c}\text { No. } \\
\text { Infected } \\
\mathbf{n = 1 9 2}\end{array}$ & $\begin{array}{c}\text { Prevalence } \\
(\mathbf{\%})\end{array}$ \\
\hline Body hygiene & & \\
Do not Wash hands before and & 62 & 32.3 \\
after eating & 53 & 27.6 \\
Do not wash hand after toilet & 29 & 15.1 \\
Walk barefooted & & \\
\hline
\end{tabular}




\section{Discussion}

Our findings indicate that the prevalence of the co-infection of urinary schistosomiasis and intestinal helminthic infections is $32.8 \%$, which is higher than what was reported in Oyo State in Nigeria (28.9\%) [24], and Cameroon (9.0\%) [25]. However, a higher prevalence of $S$. haematobium and intestinal helminths of $37.4 \%, 45.8 \%$, and $53.3 \%$ have been reported respectively $[26,27]$ in Oyo State, Maiduguri and Ogun States of Nigeria.

The occurrence of five species of parasites in this study area suggests that the prevailing environmental conditions support the transmission of a wide range of parasites. Co-infections of A. lumbricoides, hookworms, and $S$. haematobium was the most common combination in the study area. This observation is in accordance with the outcomes of Agbolade and colleagues [28] who showed that the triad of hookworm/ Ascaris / S. haematobium was common in most parts of Nigeria.

The significant association of parasite co-infection with $S$. haematobium and A. lumbricoides observed in this agrees with the findings Salawu and colleagues [24] reported an association of $A$. lumbricoides with $S$. haematobium to be most significant. The presence of these parasites in the study area could be attributed to ignorance, the customary habit of indiscriminate defecation, coupled with inadequate access to health care and basic facilities. However, with the current economic depression and dietary deficiencies, the harboring of multiple parasites by children could have considerable adverse short and long-term consequences [27].

The lack of significant association of parasite co-infection with the school could be attributed to the proximity of the schools to the river $(1 \mathrm{~km})$ and poor sanitary condition coupled with lack of personal hygiene, the absence of basic social amenities, besides the schools examined share similar environmental and cultural factors. There is also the unhygienic behavior of the pupils such as indiscriminate defecation, not washing hands before and after eating and not washing hands after the toilet. Earlier, school children normally played in or around rivers and defecation sites and most of the schools lack proper toilet facilities [26]. All these contribute to the spread of parasites.

The significant association of co-infection with gender observed in this study might be attributed to the fact that males are frequently exposed to infective places such as faecally polluted soils, infected water bodies, where they usually bath and play, these can serve as a source of infection for both urinary schistosomiasis and intestinal helminths infections. On the other hand, females are restricted by cultural and religious beliefs. The significant occurrence of parasites in male students has been reported by several authors [24, 28-30]

In the present study, a significant association of co-infection with age was observed. Pupils aged 10-12 years $(14.61 \%)$ were significantly more infected compared to pupils of other age groups. Pupils of this age group are more exposed to soils that are faecally contaminated and play around the river when fetching water or assisting their parents in irrigation farming during which they may get infected with the parasites. The significant occurrence of parasites in children aged 10-12 years reported in this present study agrees with findings [31] that found children in the age bracket $10-15$ years to be significantly more infected with parasites than children in the other age groups. However, no significant difference was found in parasite co-infection rates among different age groups [26].

The occurrence of co-infection significantly associates with water contact activity. Pupils who could not specifically mention their water contact activity recorded the highest prevalence $(16.15 \%)$. It may be these pupils engaged in many water contact activities such as bathing, washing, fetching, feeding animals and irrigation farming, thereby not certain of a particular one as to indicate as their water contact activity. These set of pupils were significantly more infected, because they may have more than one water contact activity. Several findings have indicated gender, age, and water contact activities to significantly associate with parasite occurrence $[32,33]$.

The findings of this study indicated a lack of significant association of parasite co-infection with the type of toilet. Whether pupils use open space or pit latrine they may defecate indiscriminately in school, at home or while on the farm during irrigation farming. The type of toilet system used by individuals may also serve as a risk factor for infection [33] significant association of parasite infection with bush defecation was found.

The lack of significant association in the occurrence of co-infection with nutritional status suggests equal exposure of pupils to the source of infection regardless of nutritional status. However, the significant occurrence of parasitism was found in children severely malnourished [27].

The findings of this study revealed that pupils who do not wash their hands before and after eating were significantly more infected. The reason may be attributed to the use of hands during playing in faecally polluted soil or contaminated water without washing their hands at home and in school and playing in cercariae contaminated water body through which they may get infected with infective stages of these parasites. Lack of personal hygiene may serve as a risk factor for infection.

\section{Conclusions}

Being male, 10-12 years of age and not washing hands before and after meals were the major risk factors for the spread of urinary schistosomiasis and intestinal helminths co-infection in the study area. Urinary and intestinal parasites are still being actively transmitted in the study area. These intestinal parasites might cause severe 
conditions like dysentery, dehydration, hemorrhage, anemia, appendicitis, which sometimes lead to death. Ascariasis interferes with protein digestion in children and in combination with hookworm infection or other intestinal parasites could cause, accompany or accentuate kwashiorkor. Schistosoma haematobium causes dysuria, increased frequency of micturition and haematuria (urine with blood) conditions which can eventually lead to kidney failure if untreated.

\section{Conflict of Interest}

The authors declare that there is no conflict of interest.

\section{Acknowledgements}

The authors wish to acknowledge the Wamakko Local Government Education Authority, Parents/guardians of the pupils, and Headmasters of the schools surveyed.

\section{REFERENCES}

[1] World Health Organization. Prevention and control of schistosomiasis and soil-transmitted helminthiasis. WHO Tech. Rep. 2002; Ser. 912:1-57.

[2] Steinmann P, Keiser J, Bos R, Tanner M, and Utzinger J. Schistosomiasis and water resources development systematic review, meta-analysis and estimates of people at risk. Lancet Infect. Dis 2006; 6: 411-425.

[3] de Silva NR, Brooker S, Hotez PJ, Montresor A, Engels D, and Savioli L. Soil-transmitted helminth infections: updating the global picture. Trends Parasitol.2003; 19: 547-551.

[4] World Health Organization. Tropical Disease Research (TDR). 2013. Available from https//www.who.int/tdr/en/

[5] World Health Organization. Helminth control in school-age children. A guide for managers of control programs. Second edition, 2011.

[6] Bunza, M.D.A., Bala, A.Y. and Saidu, A.R.: Vectors of Tropical Diseases: A Textbook of Parasitology, Sponsored by Tertiary Education Trust Fund (TETFUND). Printed by Usmanu Danfodiyo University Press; 2013.

[7] Vaumourin, E., Vourc'h, G., Gasqui, P. and Vayssier-Taussat, M. The importance of multiparasitism: examining the consequences of co-infections for human and animal health. Parasites \& Vectors. 2015; 8:545.

[8] Kabiru, M; Ikeh EI, Aziah I, Julia O, Fabiyi JP, and Mohammed RA. Prevalence and intensity of Schistosoma haematobium infection. A community-based survey among school children and adults in Wamakko town, Sokoto State, Nigeria. Inter J Trop Med Publ health. 2013; 2(1): 12-22.

[9] Cheesbrough M. District Laboratory practice in tropical countries. Cambridge University, Uk. 2009; pp 196.
[10] World Health Organization. Prevention and control of schistosomiasis and soil-transmitted helminthiasis. Geneva. World Health Organization. 2004; Pp. 13-28

[11] Steinmann P, Utzinger J, Du ZW, Zhou XN: Multiparasitism a neglected reality on global, regional and local scale. $A d v$ Parasitol, 2010; 73:21-50.

[12] Lello J, Boag B, Fenton A, Stevenson IR, Hudson PJ. Competition and mutualism among the gut helminthes on a mammalian host. Nature. 2013; 428:840-844.

[13] Yajima, A., Gabrielli, A.F., Montresor, A., Engels, D., Moderate and high endemicity of schistosomiasis is a predictor of the endemicity of soil-transmitted helminthiasis: a systematic review. Trans. R. Soc. Trop. Med. Hyg. 2011; $68-73$

[14] Muhammad I.A., Abdullahi, K., Bala, A.Y., Shinkafi, S.A.. The Correlation of Nutritional Status and Prevalence of Intestinal Helminthiasis among Primary School Pupils in Wamakko Local Government, Sokoto State, Nigeria. World Research Journal Biology of Biological Sciences. 2018; 3(2), 018-023.

[15] Akinseye, F.J., A.O. Egbebi and O.S. Fadare,. Challenges of soil-transmitted Helminthiasis in some communities in Ondo state, Nigeria. Int. J. Adv. Res. Biol. Sci., 2017; 4: 164-171.

[16] Auta T, Wartu JR, Jibiya BA, Jabbi AM. A comparative study on the prevalence of intestinal helminth among rural and sub-urban pupils in Gwagwada, Nigeria. Journal of Parasitology and Vector Biology. 2014; 5(6):87-91.

[17] Opara KN, Udoidung NI, Opara DC, Ekon OE. The impact of intestinal parasitic infections on nutritional status among rural and urban school-aged children in Nigeria. International Journal of Maternal and Child Health and AIDS. 2012; 1:73-82.

[18] Abelau, M., O.N. Goselle, E.O. Udeh, D.D. DPopova and T.V. Popov, (2011). A comparative study of the prevalence of helminth parasites in HIV seropositive and HIV seronegative individuals in Plateau state, Nigeria. Niger. Ann. Natural Sci., 11: 22-32.

[19] Baidoo, S.E, Tay, S.C.K., Obiri-Danso, K., Abruquah, H.H.. Intestinal helminth infection and anaemia during pregnancy: A community based study in Ghana. 2010; 2(2): 9-13

[20] Muhammad, I.A., Abdullahi, K., Bala, A.Y., Shinkafi, S.A. Prevalence of Urinary Schistosomiasis among primary school pupils in Wamakko Local Government, Sokoto State, Nigeria. The Journal of Basic and Applied Zoology. 2019; 80:22: $1-6$.

[21] Pugh RNH, Malumfashi endemic disease research project II. Ann Trop Med Parasitol. 1987; 73:295

[22] World Health Organization. The world health report, fighting disease, fostering development. 1995; 39.

[23] Cornier MA, Despre JP, Davis N, Grossmiklaus DN, Klein S, Lamarche B, Lopez-Jimenez F, Rao G, St-Onge MP, Towfighi A, and Poirier P. Assessing adiposity: a scientific statement from the American Heart Association. Circulation. 2011; 124:1996-2019.

[24] Salawu A.S, Asaolu S.O, and Sowomimo O.A. Co-infections with Schistosoma haematobium and 
soil-transmitted helminths among school-aged children in Saki, Oyo State, Nigeria. J. public health Epidemiol. 2014; 6(12): 417-423.

[25] Ntonifor HN, Green AE, Bopda MOS, and Tabot T. Epidemiology of urinary schistosomiasis and Soil-transmitted helminthiasis in a recently established focus behind mount Cameroon. Int. J. Curr. Microbiol. Appl. Sci. 2015; 4(3): 1056-1066.

[26] Morenikeji O.A, N.C. Azubike and A.O. Ige. Prevalence of intestinal and vector-borne urinary parasites in communities in the south-west, Nigeria. J. Vector Borne Dis 46. 2009; pp. $164-167$.

[27] Sulyman, M. A.., Fagbenro-Beyioku, A. F., Mafe, M. A., Akande, D. O. and Ajayi, M. B.. Schistosoma haematobium and concurrent parasitic infections in school-aged children. Niger J. Parasitol. 2009; 30(2): $79-85$.

[28] Agbolade O.M, Akinboye D.O, and Awolaja A. Intestinal helminthiasis and urinary schistosomiasis in some villages of Ijebu North, Ogun State, Nigeria. Afri J Biotech. 2004; 3(3) 206-209.

[29] Akinboye, D. O., Abdullah, A. R., Awodele, O., Akintunde,
T. I., Effedua, H. I. and Bamidele, E.. Prevalence of intestinal and urinary parasites among food handlers in Illishan-Remo, Ogun State, Nigeria. Niger J. Parasitol. 2015; 36(2): $113-118$.

[30] Timothy A, Reuben WJ, Abdulhadi, JB, and Mohammed JA J. Parasitol Vector Bio. 2014; 5(5) 87-N91.

[31] Ugbomoiko U.S, Ofoezie I. E, Okoye I. C. and Heukelbach, J. Factors associated with urinary schistosomiasis in two peri-urban communities in southwestern Nigeria. Ann Trop Med Parasitol. 2010; 104 (5) 409-419.

[32] Ladan, M.U, Abubakar R.U, Abdullahi K, Bunza M.D.A Nasiru, M, and Ladan M.J. Gender and age-specific prevalence of urinary schistosomiasis in selected villages near dam site in Gusau Local Government, Zamfara State, Nigeria. Niger J. Parasitol. 2011; 32 (1) 55-59.

[33] Ukpai, O. M. and Ahia, I. Intestinal schistosomiasis and contributory risk factors in Nsu, Ehime Mbano LGA, Imo State, Nigeria. Niger J. Parasitol. 2015; 36(3) 44-49.

[34] World Health Organization. The control of schistosomiasis. Second Report of the WHO Expert Committee. 1993; Ser No. 830. 